\title{
Erratum to: Increasing productivity and improving livelihoods in aquatic agricultural systems: a review of interventions
}

\author{
O.M. Joffre ${ }^{1}$ - S.A. Castine ${ }^{2}$ - M.J. Phillips ${ }^{2} \cdot$ S. Senaratna Sellamuttu ${ }^{3}$. \\ D. Chandrabalan ${ }^{4} \cdot$ P. Cohen ${ }^{2,5}$
}

Published online: 18 February 2017

(C) Springer Science+Business Media Dordrecht and International Society for Plant Pathology 2017

\section{Erratum to: Food Security}

DOI:10.1007/s12571-016-0633-3

This paper was published with unupdated biography of Dorothy Chandrabalan. Further, Philippa (Pip) Cohen's biography was left out during the processing. However, this was corrected as per below and the errors are no longer present in the published copies of the article.

The online version of the original article can be found at http://dx.doi. org/10.1007/s12571-016-0633-3

O.M. Joffre

o.joffre@cgiar.org

1 WorldFish, WorldFish Greater Mekong Office, \#35, Street 71 Sangkat Boeung Keng Kang 1, Phnom Penh, Cambodia

2 WorldFish, Jalan Batu Maung, Batu Maung, 11,960 Bayan Lepas, Penang, Malaysia

3 International Water Management Institute (IWMI), Southeast Asia Regional Office, Vientiane, Laos

4 Bioversity International, 43400 Serdang, Selangor Darul Ehsan, Malaysia

5 Australian Research Council Centre of Excellence for Coral Reef Studies, James Cook University, Townsville 4811, Australia

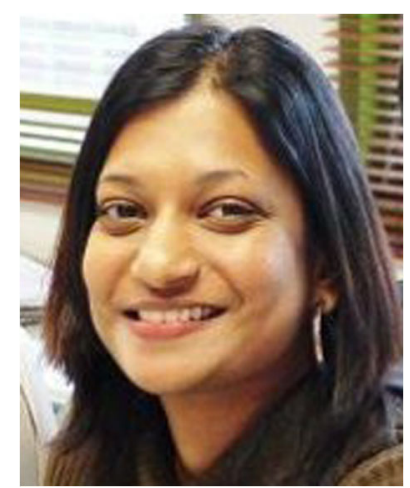

Dorothy Chandrabalan is an experienced research professional with Bioversity International, an international research organization undertaking research for development in agricultural and tree biodiversity. Since 2004, she has been engaged in numerous capacities for international and regional research projects across Asia which seek to improve livelihoods while ensuring environment and food security from the sustainable use of agriculture biodiversity. She has specialized research experience in plant biotechnology, with almost five years working in the laboratory on cryopreservation, micropropagation and molecular marker technology. Dorothy is currently pursuing her $\mathrm{PhD}$ research in the field of gender and environment management, with her research questioning how gender decision making shapes agrobiodiversity. 


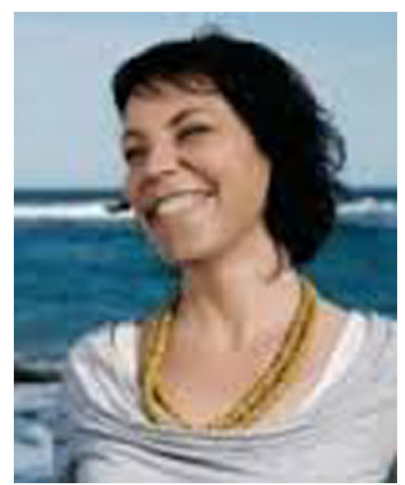

Philippa (Pip) Cohen is from Tasmania where she completed her undergrad, honours and first three years of her career in fisheries research. Pip then escaped the cold of Tasmania to the tropical Pacific - Tonga, Fiji and then Solomon Islands. Pip has worked in the Pacific now for 10 years, first as an Australian Youth Ambassador for Development, a consultant on a fisheries and development project and then a coordinator for a regional knowledge management project. In 2013 Pip completed her $\mathrm{PhD}$ at the ARC Centre of Excellence for Coral Reef Studies. Pip is now employed as a scientist for WorldFish, and is based at the ARC Centre of Excellence for Coral Reef Studies at James Cook University. Pip's research focuses on small-scale fisheries, and in particular understanding and improving community-based fisheries management for food security in the Pacific. 